\title{
The Approval-Built Collection in the Medium-Sized Academic Library
}

\begin{abstract}
The approval plan, developed and promoted by major vendors, has been variously praised and condemned in the literature. In the inflationary 1970s it continues to be used as a collection development device by libraries of all types and sizes. This study compares the approval-built collection with the collection which is created when traditional select and order procedures are used. The study was limited to 1974 imprints in four subject areas and utilized the services of two major vendors.
\end{abstract}

B OOK DEALERS, capitalizing on the library affluence of the 1960 s, developed the approval plan into its current form. As newly available federal monies suddenly rendered traditional acquisitions processes cumbersome and inadequate, the approval plan achieved fad status. Approval promised to solve the problems of the era: inadequate staffing, a booming publications rate, and large book budgets. Numbers of libraries entered into approval programs at that time with insufficient planning and information, accepting vendor promises on faith. Hysteria ensued. Some libraries abandoned approval programs entirely; and some retained and defended them, convinced the problems were minor and solvable. Others entered, canceled, and tried new vendors. The vacillation continues into the mid-1970s, an era of static budgets, dwindling federal money, and inflation. Service charges in place of discounts and vendors' financial problems contribute to the general speculation and confusion; but the approval plan continues to be used by libraries of all types and sizes, and vendors continue to expand and promote

Mary Lee DeVilbiss is university bibliographer, California State Polytechnic University, Pomona. their approval programs.

Reactions and experiences reported in the literature range from Roscoe Rouse's flat denunciation of approval plans $^{1}$ to Marion Wilden-Hart's declaration that approval plans bring in the "60 percent of the books that . . . buy themselves' " and save time for professional selection. ${ }^{2}$ The pro/con arguments have quieted since $\mathrm{H}$. William Axford and others exhorted librarians to evaluate approval buying on the basis of solid research, rather than on emotion and opinion. ${ }^{3}$ Time, the tightening budget situation, and inflation have caused both libraries and vendors to refine programs and to create more sophisticated procedures, but little research has been conducted to examine the effectiveness of approval buying as a collection development device for the academic library.

This paper, reporting the results of a one-year study in a medium-sized library, compares approval selections with traditionally created faculty and librarian selections. A secondary objective of the study was to compare the services of two major approval vendors. The events leading to the decision to conduct such a study parallel the approval experiences of other libraries. 
The Library of California State Polytechnic University, Pomona, was among those joining the approval plan rush of the 1960s and later discontinuing because of dissatisfaction with dealer service and with the effect a general approval program was having on the collection. That program, entered with a major vendor and carried for several years, presented all the typical problems reported by other libraries and will not be reviewed here. It was canceled following fruitless attempts by both the library and the vendor to solve the various problems.

The concept of approval, as a selection tool, not as an acquisitions device, remained appealing, however, because selection with book in hand seemed consistent with the goals and priorities of the collection building program. The intensive and pragmatic collection building program was instituted in 1968 during a period of rapid growth in enrollment, the emergence of new programs, and a change in status from a small agricultural and engineering college to a university retaining the agriculture, engineering, and science specialties but with strong programs and large enrollments in the social sciences and humanities. The collection building program is a joint faculty/librarian effort, and its emphasis is on development of a collection to support specifically the curricula of the institution on a modest materials budget of approximately $\$ 350,000$. Because of the budgetary constraints and a basic criterion of meeting student needs before faculty research needs, the program is philosophically highly selective and lends itself to a hand selection device such as approval. It was, however, impossible to document that hand selection from approval shipments could create a better collection than traditional select and order procedures, especially in light of the previous, unsatisfactory experience. The decision was made, therefore, to enter into a limited trial program for the purpose of comparing selections made through regular procedures with selections made from approval shipments and to compare the services of two vendors.

\section{The Trial Program}

Four subject areas in which the university has strong programs and in which the library buys heavily were chosen. The trial programs were limited to 1974 imprints for ease of data evaluation and for the purpose of delineating the length of the study. The collection development staff, agreeing in principle with LeRoy Charles Merritt that, "the quality of the collection produced ... is the true issue" 4 was faced with a need to define "quality." Defining quality is risky, of course, but for the purposes of the study, it was agreed that, because faculty and librarians know the curricula and the emphases of the academic programs and know the types of material used by students and faculty, the approval-built collection should parallel the traditionally selected collection. A "quality" approval-built collection, therefore, was defined as one which would have been created anyway as a result of faculty and librarian activity and would include, additionally, a core of other material missed by the selectors in their searches of reviews and other selection tools.

The study included the following guidelines: (1) faculty and librarians were to select and submit requests for 1974 imprints in agriculture, economics, biological sciences, and literature; (2) vendors were to ship all U.S. publications with 1974 imprints according to established profiles in these subject areas; (3) all faculty and librarian requests in the four subject areas were to be held and checked against approval receipts; (4) Cumulative Book Index (CBI) would be used as a key to publishers' output, according to profile-applicable subject headings. 
Two major vendors were chosen to supply the programs for the study, and each was given two subject areas to cover. Both vendors agreed to the limited programs with the understanding that only one vendor would be selected to supply a general program at the end of the study. Both also understood that, depending on the results of the study, the library might not enter into any general approval program at all. Both the vendors and the library agreed that a return rate higher than 5 to 10 percent would not be efficient for either vendor or library.

Vendor Number One is a major book supplier and has had approval services for several years. The company's recently revised profile descriptor is well designed and permits development of a sophisticated profile. The company provides all the standard approval services: ten-part multiple slips for each book shipped, exclusion slips, and invoicing with each shipment, etc. Economics and biological sciences were chosen for the trial program with this vendor. Librarians and the faculty in the biological sciences and economics departments were informed of the project and were asked to continue submitting request cards for 1974 imprints. As these requests came into the library, they were checked against approval receipts and held as probable future approval receipts.

Vendor Number Two has also been in the approval business for several years in the areas of science and technology, but has only recently branched out into the humanities and social sciences. The list of publishers which it supplies on approval is much smaller than that of Vendor Number One (300+ compared with $3,000+$ ). The profile modifier, which is called a thesaurus, is less complex than the modifier used by Vendor Number One, but a comparison of the two reveals little difference, if any, in the possible end re- sult. The program, as with Vendor Number One, was limited to $1974 \mathrm{im}$ prints, and agriculture and literature were chosen as the test areas for this vendor. Librarians and the agriculture and English faculty were informed of the project and were asked to continue submitting requests for 1974 imprints, without regard to the approval program.

\section{Study Results}

The results of the one-year study are difficult to analyze precisely but do provide data which reveal that dependence on approval to bring in current material may be a serious failing on the part of the library and the faculty. The study also suggests that the approvalbuilt collection will include a considerable amount of material which would never have been requested by faculty or librarian selectors and possibly will waste increasingly scarce book money.

In the biological sciences study (see Table 1), of 212 profile-applicable 1974 titles requested by faculty and librarians, only 60 were ever received on approval. The 152 titles which were never shipped by the vendor would not now be a part of the collection had the faculty and the library not continued regular selection activity and not checked approval receipts against faculty requests. In addition, of the 255 titles received as approval books, 195 were never requested by faculty or by librarians. The science bibliographer returned 33 of the 195 and accepted 162, judging them appropriate to the collection. These 162 titles may represent errors of omission in regular selection procedures or may simply reflect the slowness of reviewing and bibliographic media. It is possible that requests for many of these 162 will be forthcoming within the next two years. If, however, a good portion was purposefully not selected, it is necessary to question the expenditure. A long-term usage check will be necessary to evaluate the need for these 162 titles 
TABLE I

Vendor Number One-Trial Approval Program

\begin{tabular}{|c|c|c|c|c|c|c|c|}
\hline Subject & $\begin{array}{l}1974 \text { Titles } \\
\text { Received } \\
\text { on Approval }\end{array}$ & $\begin{array}{l}1974 \text { Titles } \\
\text { Listed } \\
\text { in } C B I^{\circ}\end{array}$ & $\begin{array}{l}\text { Titles } \\
\text { Returned } \\
\text { to Vendor }\end{array}$ & $\begin{array}{c}\text { Return } \\
\text { Percentage }\end{array}$ & $\begin{array}{l}1974 \text { Titles } \\
\text { Requested by } \\
\text { Faculty and } \\
\text { Librarians } \dagger\end{array}$ & $\begin{array}{l}1974 \text { Titles } \\
\text { Requested } \\
\text { by Faculty } \\
\text { and Received } \\
\text { on Approval } \dagger\end{array}$ & $\begin{array}{l}1974 \text { Titles } \\
\text { Requested by } \\
\text { Faculty but } \\
\text { Never Received } \\
\text { on Approval } \dagger\end{array}$ \\
\hline $\begin{array}{l}\text { Economics } \\
\text { Biological }\end{array}$ & 286 & 397 & 96 & 33.6 & 78 & 15 & 63 \\
\hline Sciences & 255 & 623 & 33 & 12.9 & 212 & 60 & 152 \\
\hline Total & $\overline{541}$ & $\overline{1,020}$ & $\overline{129}$ & $\overline{23.8}$ & $\overline{290}$ & $\overline{75}$ & $\overline{215}$ \\
\hline
\end{tabular}

- All titles listed under subject headings appropriate to the subject were counted. No attempt was made to identify titles which would have been exluded by the profile, e.g., textbooks, series other than no. 1 , etc. $\dagger$ Titles requested by faculty and librarians which fit the parameters of the profile.

and will provide some interesting data reflecting the comparative value of approval-built and traditionally built collections. In any event, the collection now contains 162 biological sciences titles with 1974 imprints which are there solely as a result of the approval plan and 152 titles which would not now be there if the library had depended on the approval plan for 1974 titles in biological sciences.

In checking 1974 CBI issues to compare recorded output of publishers with approval shipments, all titles listed under subject headings appropriate to the profile were counted. No attempt was made to identify titles which would have been excluded by the profile, e.g., textbooks, series other than the first issue, juvenile material, etc. Even considering that many of the 623 biological sciences titles listed in $C B I$ were excluded with reason, it is significant that only 255 were shipped by the vendor, and this strongly suggests vendor failure to supply what was promised. This conclusion is further documented with the evidence that 152 titles requested by faculty and librarians were never received on approval. These 152 titles obviously had appeared in reviews, announcements, and bibliographies, or they would not have been requested. Indeed, many of the 152 were actually listed in the vendor's monthly lists of available titles and were available in directorder warehouses, but not, apparently, in the approval warehouse.

The 12.9 percent return rate for biological sciences was higher than the agreed-upon optimum, but not so high as to suggest dealer inattention to the profile on shipped books. It must also be noted that none of the sixty titles requested by faculty and received on approval were returned to the vendor. This suggests the profile, as designed, was adequate for the library and that communication with the vendor could have lowered the return rate. The premise that hand selection would prevent acquisition of inappropriate material was not borne out, however. As none of the sixty titles requested by faculty and received on approval were returned to the dealer, the library saved no money as a result of hand selection in biological sciences. All returned titles were never requested by either faculty or librarians.

In economics (see Table 1) the data are more difficult to evaluate because, of the numerous 1974 titles requested by departmental faculty and by librarians, only seventy-eight could be considered to fall under the guidelines of the profile. This strongly suggests that the profile, as established, did not correctly parallel the needs of the economics curriculum. At the request of the collection development staff, vendor representatives visited the library, and the profile was adjusted as soon as this became apparent. But without immediately ex- 
panding the program to include both economics and business, it was impossible to meet departmental needs with the vendor's economics profile. The notable factor in the economics study is that the vendor never shipped, as approval books, sixty-three of the seventyeight profile-applicable titles selected by faculty and librarians. These sixty-three titles would not now be in the collection had the library depended on the approval program to bring in $1974 \mathrm{im}$ prints. Only 15 of the 286 economics titles shipped by the vendor were ever requested by faculty. Of the 286 shipped titles, 190 were accepted by the social sciences bibliographer and are now in the collection solely as a result of approval. The appropriateness of the 190 approval-selected titles to the collection will have to be evaluated by checks of faculty requests over the next two years and by usage studies.

The most annoying problem in the economics program, and one which was never resolved, was the high return rate. Many of the returned books were popular works which were totally inappropriate to an academic collection, and the dealer was never able to eliminate them from the shipments. The 33.6 percent return rate thus reflects dealer inefficiency rather than failure of the approval concept.

The 286 titles shipped, compared with the 397 profile-appropriate titles listed in $C B I$, indicates vendor coverage of available publications was much better in economics than in biological sciences, but again, the significant factor is that 63 profile-applicable and faculty-requested titles were not among the 286 titles shipped on approval.

Only one economics title requested by faculty and supplied on approval was returned as inappropriate to the collection. Since the faculty member who submitted the request did not indicate whether he selected the title from a review, an advertisement, or a bibliogra- phy, it is impossible to know whether this was a title-selected or a reviewselected choice, but it is a minor point. The notable factor is that the library saved only the price of one book as a result of hand selection.

The data on the programs with Vendor Number Two (see Table 2), agriculture and literature, cannot be evaluated as a selection device because of the limited numbers of titles received and the short duration of the programs. The literature program was canceled by the vendor four months after it was initiated due to inability to acquire material. The agriculture program was canceled by the library at the end of six months because of invoicing problems and nonreceipt of material. It is unfortunate that vendor failure obviated any analysis of these areas because agriculture is an area in which the library buys comprehensively and in which the publication rate is relatively low. Literature is an area in which the library buys extensively, but selectively, and in which the publication rate is high. Both are areas which lend themselves to the approval concept and to a study of this type. The revealing and notable factor is that a major vendor could fail so soundly to produce what was promised. (After the study was completed, Vendor Number Two canceled its approval services entirely.)

\section{ConCLusion}

In summary, the biological sciences approval program failed to bring in titles which could reasonably have been expected as approval receipts, but caused the acquisition of titles which were never requested by faculty or librarians. In economics, the approval program delivered almost none of the titles requested by faculty and librarians and caused bibliographers to spend time rejecting popular and polemic material never requested by faculty or librarians. The program in agriculture 
TABLE 2

VENDOR NUMBER Two-

Trial Approval Program

\begin{tabular}{cccc}
\hline \hline Subject & $\begin{array}{c}\text { 1974 Titles } \\
\text { Received } \\
\text { on Approval }\end{array}$ & $\begin{array}{c}\text { Titles } \\
\text { Returned } \\
\text { to Vendor }\end{array}$ & $\begin{array}{c}\text { Return } \\
\text { Percentage }\end{array}$ \\
\hline $\begin{array}{c}\text { Agriculture }{ }^{\dagger} \\
\begin{array}{c}\text { Literature } \\
\text { Total }\end{array}\end{array}$ & $\frac{76}{53}$ & $\frac{1}{10}$ & $\frac{14.28}{18.87}$ \\
\hline
\end{tabular}

- Data obtained on this program are insufficient for evaluation.

$\dagger$ Program was canceled by the library at the end of six months because of nonreceipt of material and invoicing problems.

$\ddagger$ Program was canceled by the vendor at the end of four months because of vendor inability to supply material.

provided only seven titles in a six-month period in a subject area in which the library buys comprehensively. In literature, a subject area in which the publication rate is tremendous, the approval program supplied only forty-six titles in a four-month period.

The study cannot, of course, be considered universally conclusive, because the various factors which affect book selection in any given library and the varying goals of individual libraries naturally discount the absolute validity of any single study. We are not, after all, in the business of collecting and dispensing barbed wire. The study did, however, illustrate conclusively that there are significant differences between the collection which will result from approval buying and the collection which will result from traditional select and order procedures, given current vendor service. Had Vendor Number One been able to supply, as promised, all profile-applicable titles with 1974 U.S. imprints, and had the vendor been able to eliminate popular and other inappropriate material from the shipments, the library could have expanded the program and used it to bring in current material, concentrating selection efforts on retrospective and peripheral material. The collection development staff has, however, concluded that the duplication of effort and the monitoring of approval to insure acquisition of needed material will not, for this library at least, streamline selection procedures, nor will hand selection help to spend funds more wisely. The programs have been canceled with both vendors.

Although the library is once again an approval dropout and has tried three major vendors over the past ten years, this writer is not a member of the Down With Approval Club. Any vendor will miss some titles for one reason or another and will ship some material that is inappropriate to an individual library, and it must be remembered that the library, not the dealer, is responsible for collection development. Approval buying could, given adequate vendor service, bring in a considerable amount of needed material nearly automatically. The dealer's responsibilities to the library include, however, more than just promising to deliver.

Meanwhile, librarians who believe their approval programs are bringing in the bulk of current material might do well to take a second critical look at what they are and are not receiving and at the effect approval buying is having on collections and on book budgets. Presuming that the vendor is supplying most of the current material can be as large an approval trap as the often-reported receipt and acceptance of shelfcluttering, budget-eating, and neverused material.

\section{REFERENCES}

1. Roscoe Rouse, "Automation Stops Here: A Case for Man-Made Book Collections," College \& Research Libraries 31:147-54 (May 1970).

2. Marion Wilden-Hart, "The Long-Term Effects of Approval Plans," Library Resources \& Technical Services 41:400-406 (Summer 1970).

3. H. William Axford, "The Economics of a Domestic Approval Plan," College \& Research Libraries 32:368-75 (Sept. 1971).

4. LeRoy Charles Merritt, "Are We Selecting or Collecting?" Library Resources \& Technical Services 12:140-42 (Spring 1968). 